\title{
Sorption and diffusion properties of untreated and thermally modified beech wood dust
}

\section{Jerzy Majka ${ }^{1}$ D $\cdot$ Tomasz Rogoziński $^{1}$ (D) Wiesław Olek ${ }^{1}$ (D)}

Received: 15 April 2021 / Accepted: 3 November 2021 / Published online: 13 November 2021

(C) The Author(s) 2021

\begin{abstract}
Dynamic water vapor sorption experiments were carried out using beech wood dust (from untreated and thermally modified wood) of two-particle sizes, $(<25$ and 80-250 $\mu \mathrm{m})$, obtained from abrasive sanding. Sorption isotherms were parameterized with the GAB and GDW models. Dust from thermally modified wood had significantly lower equilibrium moisture content compared to dust from untreated material, due to the reduction in primary sorption sites in treated material. The observed changes were quantified by the coefficients of the GAB and GDW models. Thermal modification and size of wood dust particles had no influence on binding energy of water molecules being linked to the secondary sorption sites. Water diffusivity decreased significantly with increasing moisture content, but only for monolayer sorption. For higher moisture content values, water diffusivity was practically independent of moisture content. These results were found for untreated and thermally modified material as well as for both dust size fractions. The influence of thermal modification on water diffusivity was unclear, which is attributed to the diffusion model, which represents dust particles as spheres and assumes instant hygroscopic equilibrium. Overall, this study indicates that the effectiveness of filtration processes likely depends strongly on sorption and diffusion properties of wood dust only at low moisture contents within the hygroscopic range.
\end{abstract}

\section{Abbreviations}

$\begin{array}{ll}a(\mathrm{~cm}) & \text { Sphere radius } \\ C_{G A B}(-) & \text { Equilibrium constant related to monolayer sorption (GAB model) } \\ d(\mu \mathrm{m}) & \text { Equivalent diameter of dust particles } \\ D\left(\mathrm{~cm}^{2} / \mathrm{s}\right) & \text { Water diffusivity } \\ E(-) & \text { Reduced water content } \\ E M C(\mathrm{~kg} / \mathrm{kg}) & \text { Equilibrium moisture content of wood dust }\end{array}$

Wiesław Olek

olek@up.poznan.pl

1 Faculty of Forestry and Wood Technology, Poznań University of Life Sciences, ul. Wojska Polskiego 38/42, 60-637 Poznań, Poland 


\begin{tabular}{|c|c|}
\hline$\triangle E M C(\mathrm{~kg} / \mathrm{kg})$ & $\begin{array}{l}\text { Maximum difference of equilibrium moisture content for desorp- } \\
\text { tion and adsorption }\end{array}$ \\
\hline$H$ (arb. units) & Sorption hysteresis loop \\
\hline$K_{G A B}(-)$ & Equilibrium constant related to multilayer sorption (GAB model) \\
\hline$k_{G D W}(-)$ & $\begin{array}{l}\text { Kinetic constant related to sorption on secondary sites (GDW } \\
\text { model) }\end{array}$ \\
\hline$K_{G D W}(-)$ & $\begin{array}{l}\text { Kinetic constant related to sorption on primary sites (GDW } \\
\text { model) }\end{array}$ \\
\hline$m_{G D W}(\mathrm{~kg} / \mathrm{kg})$ & $\begin{array}{l}\text { Monolayer water content, i.e., the maximum content of water } \\
\text { bound to primary sites (GDW model) }\end{array}$ \\
\hline$M_{m}(\mathrm{~kg} / \mathrm{kg})$ & Monolayer capacity (GAB model) \\
\hline$M C(\mathrm{~kg} / \mathrm{kg})$ & Moisture content \\
\hline$q_{3}(\%)$ & Density distribution of particles \\
\hline$Q_{3}(\%)$ & Cumulative particle size distribution \\
\hline$R H(-)$ & Air relative humidity \\
\hline$w(-)$ & $\begin{array}{l}\text { Ratio of water molecules bound to primary sites and converted } \\
\text { into secondary sites (GDW model) }\end{array}$ \\
\hline$\tau(\mathrm{s})$ & Time \\
\hline
\end{tabular}

\section{Introduction}

Wood dust formed during abrasive sanding and by other means was recognized as a carcinogenic agent as early as 1994 (e.g., Meng et al. 2020). Wood dust particles, which are spread around workplaces, can also cause numerous other diseases (e.g., Jacobsen et al. 2010). Therefore, the application of dust exhaust systems has special importance for worker safety. Exhaust system components are located outside buildings to reduce the risk of fire. Under these conditions, dynamic interactions of wood dust with moist air cause water gain by wood dust when air cools as it is expelled to baghouse dust collectors. Under these circumstances, the effectiveness of filtration systems is often reduced by dust cake formation.

The filtration performance can be significantly affected by physical properties of gas. The effect of the air humidity on the filter performance depends on the filter type, gas properties, size and chemical composition of dust particles. Changes in air humidity induce variation in pressure drop, dust cake removal and filtration efficiency (Gupta et al. 1993; Schmidt and Pilz 1996; Hajra et al. 2003; Park et al. 2007). These problems are already found in the hygroscopic range and become more significant when condensation occurs. The presence of moisture during the filtration process leads to blinding and reduction in the life cycle of filter bags. Water condensation from air is responsible for forming a dust cake, which is difficult to clean. The dust cake adhesion strongly depends on the presence of water in the liquid phase. It induces higher energy demand for removing the dust cake. On the other hand, the blinding of the filter bags enhances filtration efficiency. Thanks to this, it is possible to reduce the content of carcinogenic wood dust particles in the air recycled into workplaces. However, other methods to reduce the concentration of dust should be chosen in order to reduce energy consumption 
and increase the life cycle of filter bags (Morris and Allen 1996; Chen et al. 2001; Mukhopadhyay 2009, 2010; Simon et al. 2014).

The hygroscopic and diffusion properties of dust acquired from beech wood were previously reported by Majka et al. (2019). However, that study considered dust obtained from untreated wood, while thermally modified wood has grown in popularity due to its reduced environmental impact compared to chemically modified wood and the desirable attributes of the product. Jones and Sandberg (2020) recently pointed out that thermal modification is the most common approach to wood modification. Thermal modification reduces wood hygroscopicity mainly by the removal of hydroxyl groups from degraded hemicellulose (e.g., Altgen et al. 2016; Liang and Wang 2016). Hemicellulose degradation also improves dimensional stability, which is attributed to ultrastructural changes in treated material (although some results suggest that cross-linking does not improve dimensional stability; e.g., Kocaefe et al. 2015).

The desirable properties of thermally modified wood are accompanied by a general decrease in favorable mechanical properties. Treated wood is more brittle due to the degradation of amorphous components (Esteves and Pereira 2009). Moreover, tensile strength and bending strength significantly decrease after treatment (e.g., Boonstra et al 2007). The mechanical properties of heat-treated wood also influence machining processes, including sawing and sanding. Only a few studies have analyzed wood dust obtained from thermally modified wood. Those analyses mainly focused on the particle size distribution of wood dust obtained from untreated and thermally modified wood. Aro et al. (2019) studied wood dust particle size obtained during sawing of thermally modified wood. They found that treatment had a minor influence on the size distribution of dust particles. Piernik et al. (2019) analyzed the effect of thermal modification and wood machining on wood dust formation, with higher treatment temperature increasing the production of the finest particles, which are a potential threat to workers' health. A similar relationship was found by Očkajová et al. (2020), i.e., at higher treatment temperature values; there was an increase in the finest particle size of wood dust. Another problem in evaluating wood dust is differences in its properties for different wood species and with different machining operations, i.e., sawing (Aro et al. 2019) or milling (Očkajová et al. 2020; Piernik et al. 2019). The use of different laboratory grinders is one method for obtaining experimental material (e.g., Yuan et al. 2021), but this can produce significant differences in the shape and properties of wood dust particles.

Little is known about the hygroscopic properties of wood dust from thermally modified wood. Källbom et al. (2018) is the only study we are aware of that analyzed hygroscopicity of sawdust, in that case for heat-treated Norway spruce wood, with sorption isotherms evaluated over three adsorption-desorption cycles. They reported that equilibrium moisture content reduction is partially reversible. In comparison, the hygroscopic properties of thermally modified solid wood have been extensively studied. Olek et al. (2013) stated that monolayer moisture sorption was responsible for reduced equilibrium moisture content of thermally treated wood. It was also found that sorption hysteresis increased after wood modification, which was attributed to ultrastructural reorganization of wood. 
Hygroscopic water transport in thermally modified solid wood has been examined less often. Pfriem et al. (2010) recognized non-Fickian behavior in thermally modified solid wood. Olek et al. (2016) applied the inverse method for analyzing water diffusion in native and thermally modified wood. Non-Fickian behavior was significant for heat-treated material, which was explained as being caused by a delay in obtaining hygroscopic equilibrium, compared to unmodified wood. To the authors knowledge, a joint analysis of sorption isotherms and water diffusion in wood dust particles from thermally modified wood has not yet been reported.

The primary objective of this study was to determine sorption properties of dust particles produced by abrasive sanding of untreated and thermally modified beech wood. In addition, it was sought to quantify sorption properties by modeling sorption isotherms, which were used to design dynamic sorption experiments that could elucidate water diffusivity in wood dust.

\section{Materials and methods}

\section{Thermal modification}

European beech (Fagus sylvatica L.) wood was kiln dried to a moisture content of ca. $12 \%$ to prepare it for use in experiments. The material was then divided into two parts, one part was untreated and the other one subjected to thermal modification, which was done for samples having a cross section of ca. 40-50 mm and length of $300 \mathrm{~mm}$. Thermal modification was carried out in a laboratory kiln (Olek et al. 2013). The first phase of heating was performed in moist air until the wood temperature reached ca. $130{ }^{\circ} \mathrm{C}$. The second, main, phase of heating was done in superheated steam until reaching the target temperature of $220{ }^{\circ} \mathrm{C}$. The duration of the main phase was $2 \mathrm{~h}$ during which the target temperature was maintained. After completing the main phase of treatment, the material was cooled, first in superheated steam and then in moist air.

\section{Dust sample preparation}

Wood dust was obtained from untreated and thermally modified solid wood by abrasive belt sanding along the direction of the wood grain. Wood dust was then sieved to separate the particles into fractions of distinctly different particle sizes, i.e., (a) $<25$ and (b) 80-250 $\mu \mathrm{m}$. An AS 200 Digit (Retsch, Germany) sieving machine was used to separate the dust fractions and a laser particle sizer (Analysette 22 Microtec Plus, Fritsch, Germany) quantified particle size distributions within each fraction. The cumulative particle size distribution $\left(Q_{3}\right)$ and density distribution $\left(q_{3}\right)$ are presented in Fig. 1 for unmodified and thermally modified wood. MaScontrol (Fritsch, Germany) software was used to calculate the diameter $(d)$ of dust particles, with average diameter values of 22.75 and $24.99 \mu \mathrm{m}$ for wood dust $<25 \mu \mathrm{m}$ from untreated and thermally modified wood, respectively. Average diameters of the 80-250 $\mu \mathrm{m}$ fraction were 142.43 and $135.37 \mu \mathrm{m}$ for untreated and thermally modified wood, 
Fig. 1 Cumulative particle size distribution $\left(Q_{3}\right)$ and density distribution $\left(q_{3}\right)$ of untreated and thermally modified beech wood dust fractions

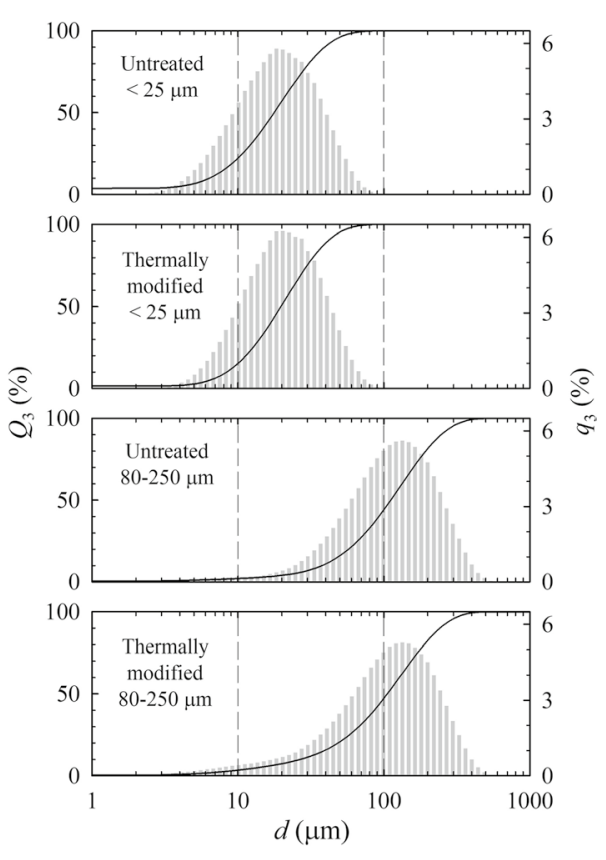

respectively. Wood dust particle dimensions were smaller than the anatomical elements found in beech wood tissue. For example, the diameter of dust particles in each fraction was significantly lower than the mean length of fibers $(600-1300 \mu \mathrm{m})$ and vessels (300-700 $\mu \mathrm{m}$ ) of beech wood (Wagenführ 2006). Moreover, particle size analysis clearly showed that the dimensions of the smallest particles were less than the diameter of fibers and vessels, i.e., 16-20 $\mu \mathrm{m}$ and 10-85 $\mu \mathrm{m}$, respectively (see Fig. 1).

\section{Sorption experiments}

Prior to testing, dust samples from untreated and thermally modified beech wood were stored in desiccators over phosphorus pentoxide to bring them close to a dry state. The initial mass of dust samples was ca. $7 \mathrm{mg}$. Sorption experiments were carried out in a dynamic vapor sorption apparatus (DVS Advantage 2, Surface Measurement Systems, London, the UK) at $25{ }^{\circ} \mathrm{C}$. The experiments always started with samples equilibrated in dry gas in order to obtain a dry initial state. Equilibrium moisture content $(E M C)$ values were measured at 11 levels of gas relative humidity $(R H)$, ranging from 0 to $95 \%$. The DVS apparatus uses two different options of a stop criterion, i.e., fixed time for a stage of a sorption experiment or a criterion based on the rate of mass change over a specified duration, which is applied at each $R H$ level. The application of the fixed time criterion results in the problem that a stage lasts for a specified period of time regardless of the equilibrium state of a sample. Therefore, the rate of mass change over a specified duration was used in the study 
as the stop criterion. The default stop value of $0.002 \% / \mathrm{min}$ over a $10 \mathrm{~min}$ window used in DVS Sorption Solution software was criticized by Glass et al. (2017, 2018) because it results in unacceptable errors in EMC estimation. Therefore, a modified stop criterion $(0.001 \% / \mathrm{min}$ with time window of $10 \mathrm{~min}$ and the minimum stability period of $60 \mathrm{~min}$ ) was used in the present study. The analysis of the absolute error (uncertainty) of moisture content was performed to derive the criterion. The total differential method (e.g., Taylor 1997) was used to analyze the error. The current modified stop criterion is shorter than the recommendation of $0.0003 \% \mathrm{~min}^{-1}$ over $2 \mathrm{~h}$ and given by Glass et al. (2018), because wood dust approaches equilibrium more quickly than solid wood.

\section{Sorption isotherm modeling}

Adsorption and desorption isotherms were constructed for the four wood dust sample types (modified or unmodified and large or small size) and parametrized with the GAB (Basu et al. 2006) and GDW (Furmaniak et al. 2007a,b) models. The threeparameter GAB model was applied in the form:

$$
E M C=M_{m} \frac{K_{G A B} \cdot C_{G A B} \cdot R H}{\left(1-K_{G A B} \cdot R H\right) \cdot\left(1-K_{G A B} \cdot R H+C_{G A B} \cdot K_{G A B} \cdot R H\right)}
$$

where $E M C$-equilibrium moisture content, $M_{m}(\mathrm{~kg} / \mathrm{kg})$-monolayer capacity, $C_{G A B}$-equilibrium constant related to monolayer sorption, and $K_{G A B}$-equilibrium constant related to multilayer sorption. The model describes water molecule bonding to sorption sites to form a monomolecular layer. Water molecules in the monolayer become secondary sorption sites, and additional layers of water are formed (multilayer sorption).

The GDW model assumes the existence of the primary sorption sites on the adsorbent surface. It also postulates that water molecules bonded to those sites are converted into the secondary ones. However, the most important difference between the GAB and GDW models concerns the potential absorption of more than one water molecule by secondary sites. The four-parameter form of the GDW model is given by:

$$
E M C=\frac{m_{G D W} \cdot K_{G D W} \cdot R H}{\left(1+K_{G D W} \cdot R H\right)} \cdot \frac{1-k_{G D W} \cdot(1-w) \cdot R H}{\left(1-k_{G D W} \cdot R H\right)}
$$

where $m_{G D W}(\mathrm{~kg} / \mathrm{kg})$-monolayer water content (the maximum content of water bound to primary sites), $K_{G D W}$-kinetic constant related to sorption on primary sites, $k_{G D W}$-kinetic constant related to sorption on secondary sites, $w$-ratio of water molecules bound to the primary sites that become secondary sorption sites. The GDW model considers three scenarios of sorption, expressed through the $w$ parameter: (a) $w<1$-water molecules absorbed on primary sites are not completely converted into secondary sorption sites, (b) $w=1$-all monolayer water molecules are converted into secondary sorption sites (in this case, the GDW model is reduced 
to the GAB model), and (c) $w>1$ - each monolayer water molecule is statistically converted into more than one secondary sorption site.

\section{Diffusivity determination}

As $R H$ changes cause varying changes in $E M C$, the adsorption isotherms were used to design experiments for collecting data for diffusivity determination. The $R H$ changes to be tested were determined to obtain even ranges of EMC. Data to estimate diffusivity were obtained from experiments made in the DVS apparatus in adsorption mode. The stepwise increase in $R H$ was programmed to obtain a final $E M C$ of $0.01 \mathrm{~kg} / \mathrm{kg}$ at the end of the first adsorption stage, with the sample mass measured every $60 \mathrm{~s}$. The test was terminated when the rate of mass change was less than $0.001 \% / \mathrm{min}$ over $60 \mathrm{~min}$. After finishing the first sub-experiment, $R H$ was increased successively, with a total of 15 sub-experiments performed up to the maximum target $E M C$ of $0.15 \mathrm{~kg} / \mathrm{kg}$. The results of the sub-experiments provided sets of input data for diffusivity determination.

Although wood dust particles can have a range of complex shapes, they are commonly modeled as spheres. The assumption of spherical shape was used in solving the initial-boundary-value problem of diffusion. Transient diffusion was described by Fick's second law, with boundary condition of the first kind and the initial condition assuming uniform water content. A simplified solution of the diffusion problem derived by Peppas and Brannon-Peppas (1994) valid for short time behavior of the process, i.e., for $E<0.8$ was applied, where:

$$
E=6\left(\frac{D \tau}{a^{2}}\right)^{\frac{1}{2}}\left\{\pi^{-\frac{1}{2}}+2 \sum_{n=1}^{\infty} \operatorname{ierfc} \frac{n a}{\sqrt{D \tau}}\right\}-3 \frac{D \tau}{a^{2}} \cong 6\left(\frac{D \tau}{\pi a^{2}}\right)^{\frac{1}{2}}-3 \frac{D \tau}{a^{2}}
$$

with $a$-sphere radius, $D$-water diffusivity, $E$-reduced water content, and $\tau$ time. Water diffusivity values were obtained by fitting Eq. (3) to the results of the sorption sub-experiments.

Although it was already recognized that the thermal treatment of wood implies highly non-Fickian behavior the classic form of Fick's second law together with the simplified analytical solution was used in the study. Olek et al. $(2011,2016)$ developed the modification of the diffusion model for non-Fickian behavior. The model accounted for an increased delay in obtaining the hygroscopic equilibrium of thermally modified wood. A relaxation mechanism was incorporated into the convective boundary condition of the model. Unfortunately, the model can be solved with numerical methods only. The implementation of the model for wood dust seems to be impossible. 


\section{Results}

\section{Sorption isotherms}

EMC measurements taken with the DVS apparatus provided data for individual sorption modes, i.e., adsorption and desorption. The discreet values of EMC were acquired after approaching the hygroscopic equilibria for prescribed $R H$ levels at $25{ }^{\circ} \mathrm{C}$. Sorption isotherms of untreated and thermally modified wood dust plotted after parameterization with the GAB model are presented in Fig. 2. Each plot depicts two sets of isotherm loops for wood dust fractions $<25 \mu \mathrm{m}$ and 80-250 $\mu \mathrm{m}$. The depicted isotherms formed closed loops. The EMC was influenced by particle size; higher $E M C$ values were obtained for smaller particles of the same material, for both untreated and thermally modified wood dust. The influence of particle size was similar to that reported for dust of unmodified beech wood (Majka et al. 2019). A distinct reduction in EMC values was observed for thermally modified wood dust. Differences in $E M C$ were quantified in detail by modeling sorption isotherms.

The three-parameter GAB and four-parameter GDW adsorption and desorption isotherm models were separately fitted for the four experimental options (two wood dust size fractions of untreated and thermally modified material). Coefficients of the best-fit sorption algorithms for each model were estimated using the Levenberg-Marquardt algorithm with SigmaPlot 9.0 software. The results of isotherm parametrization with both models are presented in Tables 1 and 2.

Thermal modification affected monolayer water content estimated using the GAB model during adsorption. The values of the $M_{m}$ coefficient were reduced from 0.052 to $0.041 \mathrm{~kg} / \mathrm{kg}$ for the dust fraction $<25 \mu \mathrm{m}$ and from 0.047 to $0.035 \mathrm{~kg} / \mathrm{kg}$ for the $80-250 \mu \mathrm{m}$ fraction (Table 1). This supports the hypothesis that thermal
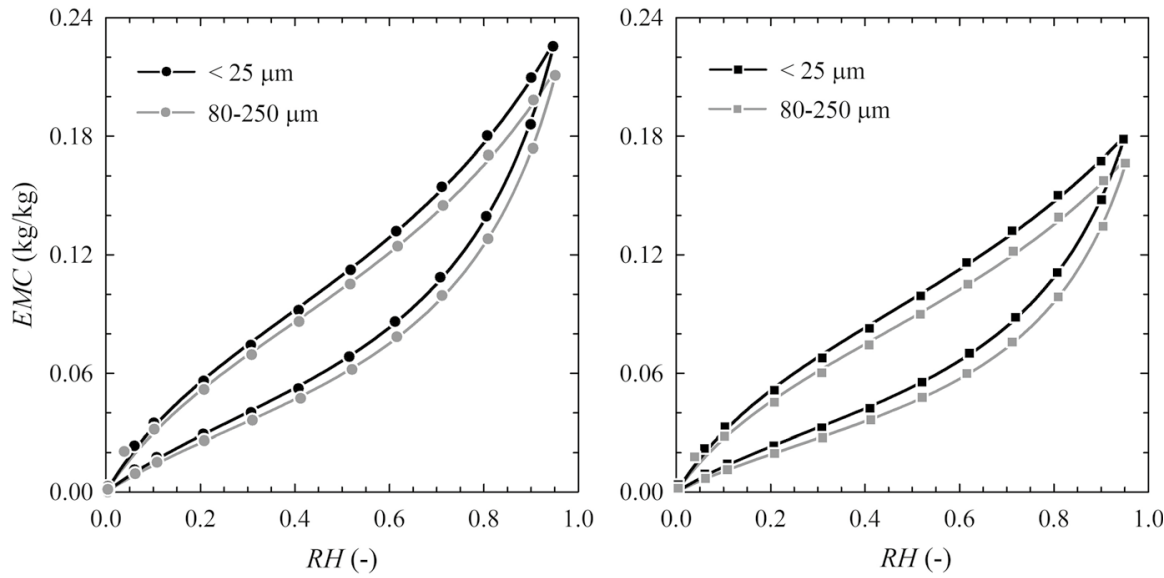

Fig. 2 Sorption isotherms of untreated (left) and thermally modified (right) beech wood dust at $25{ }^{\circ} \mathrm{C}$. Adsorption and desorption isotherms were parametrized with the GAB model, and symbols represent experimental data separately measured for each treatment option and dust fraction 
Table 1 Estimated coefficients of the GAB model for two fractions of untreated and thermally modified wood dust

\begin{tabular}{lllllll}
\hline $\begin{array}{l}\text { Wood dust } \\
\text { fraction }(\mu \mathrm{m})\end{array}$ & Treatment option & Sorption phase & $M_{m}(\mathrm{~kg} / \mathrm{kg})$ & $K_{G A B}$ & $C_{G A B}$ & $R^{2}$ \\
\hline$<25$ & Untreated & Adsorption & 0.052 & 0.827 & 4.215 & 0.9998 \\
& & Desorption & 0.100 & 0.636 & 6.485 & 0.9997 \\
& \multirow{2}{*}{ Thermally modified } & Adsorption & 0.041 & 0.826 & 4.412 & 0.9998 \\
& & Desorption & 0.096 & 0.554 & 7.261 & 0.9991 \\
& \multirow{3}{*}{ Un-250 } & Adsorption & 0.047 & 0.830 & 3.891 & 0.9999 \\
& \multirow{2}{*}{ Thermally modified } & Adsorption & 0.035 & 0.841 & 4.068 & 0.9998 \\
& & Desorption & 0.086 & 0.574 & 6.865 & 0.9983 \\
\hline
\end{tabular}

Table 2 Estimated coefficients of the GDW model for two fractions of untreated and thermally modified wood dust

\begin{tabular}{|c|c|c|c|c|c|c|c|}
\hline $\begin{array}{l}\text { Wood dust } \\
\text { fraction } \\
(\mu \mathrm{m})\end{array}$ & Treatment option & Sorption phase & $m_{\mathrm{GDW}}(\mathrm{kg} / \mathrm{kg})$ & $K_{\mathrm{GDW}}$ & $k_{\mathrm{GDW}}$ & $w$ & $R^{2}$ \\
\hline \multirow[t]{4}{*}{$<25$} & \multirow[t]{2}{*}{ Untreated } & Adsorption & 0.0563 & 3.4607 & 0.8175 & 1.2294 & 0.9998 \\
\hline & & Desorption & 0.0691 & 7.4875 & 0.5155 & 2.8585 & 0.9999 \\
\hline & \multirow[t]{2}{*}{ Thermally modified } & Adsorption & 0.0452 & 3.5418 & 0.8168 & 1.1990 & 0.9999 \\
\hline & & Desorption & 0.0471 & 12.145 & 0.2855 & 8.3725 & 0.9999 \\
\hline \multirow[t]{4}{*}{$80-250$} & \multirow[t]{2}{*}{ Untreated } & Adsorption & 0.0723 & 2.0480 & 0.8352 & 0.8845 & 0.9999 \\
\hline & & Desorption & 0.0570 & 8.7041 & 0.4752 & 3.8451 & 0.9999 \\
\hline & \multirow[t]{2}{*}{ Thermally modified } & Adsorption & 0.0655 & 1.6654 & 0.8555 & 0.7176 & 0.9998 \\
\hline & & Desorption & 0.0295 & 25.048 & 0.2753 & 13.777 & 0.9998 \\
\hline
\end{tabular}

modification reduces active sorption sites. Moreover, $M_{m}$ was always lower for adsorption compared to desorption.

The $C_{G A B}$ coefficient is related to sorption enthalpy of the monolayer water. Values of this coefficient were higher than 2 in all analyzed isotherms. This satisfies the necessary condition for classifying these as type II isotherms. Lewicki (1997) states that type II isotherms should also satisfy the following two inequalities, in which $5.57 \leq C_{G A B}<\infty$ and $0.24<K_{G A B} \leq 1$. These additional conditions were met for desorption isotherms only. Therefore, the adsorption isotherms cannot be fully classified as type II. The observed values of $C_{G A B}$ were always significantly higher than $K_{G A B}$ in corresponding isotherms (Table 1). This suggests that monolayer water molecules might be much stronger bound than those with multilayer bonding (e.g., Hess et al. 2018). Thermal modification increased $C_{G A B}$ for isotherms both in adsorption and desorption as well as for both size fractions of particles. This can be interpreted as meaning that thermal treatment increases the binding strength of water molecules in the monolayer. Some decrease in $C_{G A B}$ 
was found for larger dust particles, suggesting that monolayer water molecules are less tightly bound in larger wood dust particles. Higher $C_{G A B}$ values were noticed during desorption compared to adsorption (Table 1). This was observed for untreated and thermally modified wood as well as for both size fractions of wood dust. Hess et al. (2018) attributed differences in $C_{G A B}$ values for desorption and adsorption to sorption hysteresis.

The coefficient $K_{G A B}$ indicates the difference between the free enthalpy of multilayer water molecules and bulk water (Timmermann 2003). Values of $K_{G A B}$ were lower than 1 for all isotherms (Table 1), i.e., the necessary condition for preserving the physical soundness of the parameter was satisfied (e.g., Chirife et al. 1992). Higher values of $K_{G A B}$ indicate higher heat of sorption of multilayer water. It was observed during adsorption that neither thermal modification nor size of wood dust particles influenced the binding energy of water molecules during multilayer sorption. In the case of desorption, a decrease in $K_{G A B}$ was observed for thermally modified wood dust, while particle fraction had again no influence on the coefficient.

The influence of thermal modification on the reduction of water content in the monolayer was also evident when analyzing the GDW model. This reduction was evident from the lower maximum content of water bound to primary sites $\left(m_{G D W}\right)$, which has a similar physical meaning to that of the $M_{m}$ coefficient in the GAB model. Values of $m_{G D W}$ were significantly lower with thermal modification for both adsorption and desorption as well as for both wood dust size fractions (Table 2). A similar reduction in monolayer water was found for thermally modified solid wood (Olek et al. 2013). The phenomenon can be explained by dehydration reactions of hemicelluloses, which are the most hygroscopic components of wood (Esteves and Pereira 2009), as well as by ultrastructural changes in wood components (Olek and Bonarski 2014).

Values of the $w$ parameter in the GDW model were analyzed for the adsorption mode only as wood dust during its transport in the filtration installations only gains water. The $w$ parameter is a measure of water molecules bound to primary sites that are converted into secondary ones. It indicates water gain and the creation of secondary sorption sites for binding water. For this reason, the analysis of $w$ in desorption mode is questionable. The $w$ parameter was less than 1 for the larger fraction $(80-250 \mu \mathrm{m})$ of both untreated and thermally modified wood dust. This can be interpreted as indicating that not all primary sites are converted into secondary ones. Moreover, conversion ability decreased after thermal modification (Table 2). The number of secondary sites is smaller than the number of primary sites. In the case of the smaller dust fraction $(<25 \mu \mathrm{m}), w$ was slightly greater than one, indicating that each water molecule bound to a primary sorption site was able to create more than one secondary site, promoting the formation of water clusters. Thermal modification only slightly decreased clustering ability. The values of $w$ obtained for both size fractions of wood dust were significantly greater than has been reported for solid wood, for softwood species by Furmaniak et al. (2008) and especially for beech wood (Olek et al. 2013). Therefore, the mechanism of water molecules bonding on the secondary sorption sites in wood dust particles differs from that observed for solid wood, where clustering ability was practically not observed. 
The applied GDW model was also used to classify sorption isotherms. Furmaniak et al. (2011) proposed an arbitrary criterion for distinguishing type II and type III isotherms. In the present study, $K_{G D W}$ was higher than unity for all treatment options. Therefore, all isotherms were classified as type II.

Sorption hysteresis was quantified with the hysteresis loop $(H)$, the maximum difference of equilibrium moisture content for desorption and adsorption $(\triangle E M C)$ and corresponding relative humidity $(R H)$ (Majka et al. 2016). The determined $\triangle E M C$ and corresponding $R H$ values accounted for the $E M C$ data obtained from the absorption isotherms being determined from the dry state and the scanning desorption isotherm initiated from $R H$ of $95 \%$. Therefore, the $\triangle E M C$ values were used for comparing the hysteresis phenomenon for each option of the sorption experiments. The estimated coefficients of hysteresis are presented in Table 3. Thermal modification significantly reduced hysteresis in both fractions of beech wood dust, as measured using the hysteresis loop. The significant influence of thermal modification on sorption hysteresis was also supported by values of the maximum difference of equilibrium moisture content for desorption and adsorption $(\triangle E M C)$. This estimator clearly indicated much greater influence of thermal modification on sorption hysteresis in wood dust, compared to solid wood. The phenomenon was found for both wood dust size fractions.

\section{Water diffusivity}

Water diffusivity was studied for four sets of sorption experiments, i.e., for two size fractions of wood dust from untreated and thermally modified material. The values of the equivalent spherical diameter $(d)$ of wood dust particles, as determined using MaScontrol software, were used to determine diffusivity according to the concept proposed by Ritger and Peppas (1987) for analyzing diffusion processes in particles of different sizes. The sets of input data for diffusivity determination were collected from 15 adsorption sub-processes. Adsorption isotherms obtained in the present study were used to design experiments in which changes in $R H$ were selected so that each adsorption sub-process corresponded to a uniform range of wood dust moisture contents of ca. $0.01 \mathrm{~kg} / \mathrm{kg}$. The procedure enabled determination of the dependence of diffusivity on moisture content (Fig. 3).

Table 3 Sorption hysteresis loop $(H)$, maximum difference of equilibrium moisture content for desorption and adsorption $(\triangle E M C)$ and corresponding relative humidity $(R H)$ for unmodified and thermally modified beech wood dust fractions at $25^{\circ} \mathrm{C}$

\begin{tabular}{lllll}
\hline $\begin{array}{l}\text { Wood dust fraction } \\
(\mu \mathrm{m})\end{array}$ & Treatment option & $H$ (arb. units) & $\Delta E M C(\mathrm{~kg} / \mathrm{kg})$ & $R H(-)$ \\
\hline$<25$ & Untreated & 0.0329 & 0.054 & 0.69 \\
& Thermally modified & 0.0237 & 0.037 & 0.66 \\
$80-250$ & Untreated & 0.0297 & 0.050 & 0.69 \\
& Thermally modified & 0.0218 & 0.034 & 0.67 \\
\hline
\end{tabular}


Fig. 3 Water diffusivity of unmodified and thermally modified beech wood dust $(<25 \mu \mathrm{m}$ fraction-top and 80-250 $\mu \mathrm{m}$ fraction-bottom) as a function of moisture content (measured at $25{ }^{\circ} \mathrm{C}$ )

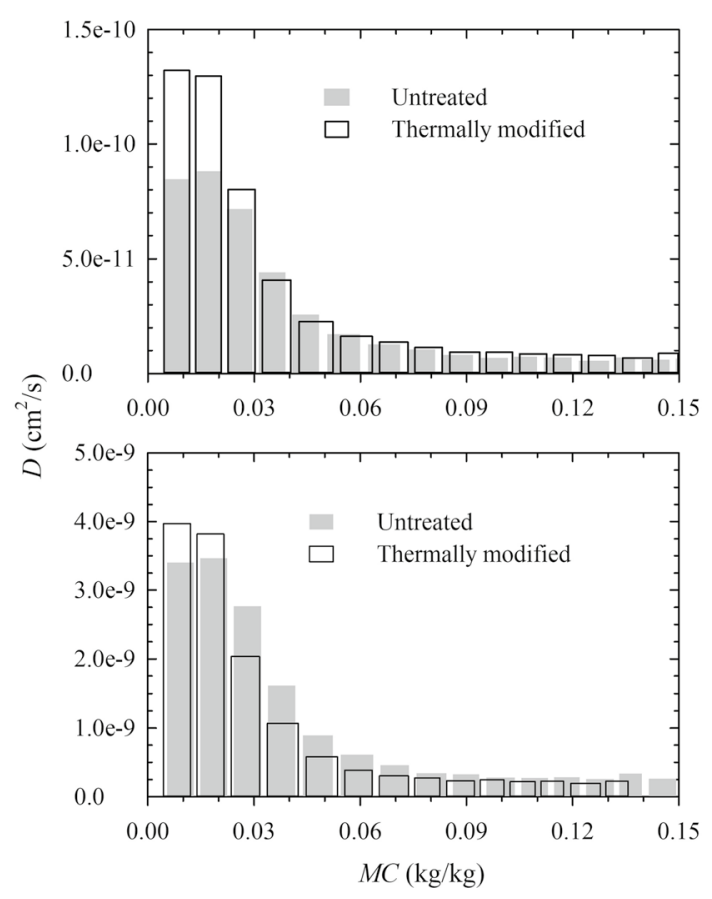

Table 4 Maximum values of diffusivity for unmodified and thermally modified beech wood dust fractions at $25^{\circ} \mathrm{C}$

\begin{tabular}{llllr}
\hline $\begin{array}{l}\text { Wood dust frac- } \\
\text { tion }(\mu \mathrm{m})\end{array}$ & Treatment option & Treatment & Diffusivity $D\left(\mathrm{~cm}^{2} / \mathrm{s}\right)$ & $R^{2}$ \\
\hline$<25$ & Untreated & Unmodified & $8.82 \cdot 10^{-11}$ & 0.9918 \\
& Thermally modified & Modified & $1.32 \cdot 10^{-10}$ & 0.9728 \\
$80-250$ & Untreated & Unmodified & $3.40 \cdot 10^{-9}$ & 0.9741 \\
& Thermally modified & Modified & $3.97 \cdot 10^{-9}$ & 0.9743 \\
\hline
\end{tabular}

The large number of observations of water content over time within the sorption sub-experiments allowed us to obtain high accuracy when fitting data to Eq. (3) and in determining water diffusivity. Much higher values of diffusivity were found for larger particles (Fig. 3, Table 4). This was consistent with the results of GAB model analysis, as $C_{G A B}$ values were lower for the $80-250 \mu \mathrm{m}$ fraction. This was interpreted as indicative of lower mobility of water molecules in the monolayer in larger wood dust particles.

The highest values of diffusivity were found for the lowest values of moisture content, when water molecules were primarily bound to primary sorption sites. This was observed for both size fractions and for untreated and thermally modified wood. As moisture content increased and formation of the water monolayer 
proceeded, diffusivity significantly decreased until reaching a moisture content of ca. $0.06 \mathrm{~kg} / \mathrm{kg}$. This threshold corresponds to the maximum content of water bound to primary sites $\left(m_{\mathrm{GDW}}\right)$ in the GDW model, estimated during adsorption (Table 2). After the monolayer was completely formed, there was a less significant decrease in diffusivity. This marked the beginning of the formation of additional layers of water. The decrease in diffusivity practically stopped at a moisture level of ca. $0.09 \mathrm{~kg} / \mathrm{kg}$. At higher moisture contents, diffusivity was fairly constant, which was probably related to decreased availability of secondary sorption sites with increasing moisture content and its influence on slowing diffusion rates.

The changes in diffusivity as a function of moisture content were found for both size fractions of wood dust as well as for untreated and thermally modified material. However, high differences in diffusivity were found for wood dust based on size. The influence of the size of wood dust was quantified by the ratio of the maximum values of diffusivity for the largest and smallest particles. Values of this ratio were calculated for data shown in Table 4, being equal to ca. 40 for untreated wood dust and ca. 30 for thermally modified material. Similar relations were reported for untreated wood dust at different temperatures during adsorption experiments (Majka et al. 2019).

The influence of thermal modification on water diffusivity was not clear. This probably was due to the fact that the diffusion model assumes wood dust particles were spherical, while the actual shapes of particles highly deviate from this assumption. It was previously found that the shape of wood dust particles is diverse, including irregular, conical, rectangular, cylindrical and spherical shapes (Gómez Yepes and Cremades 2011). Mazzoli and Favoli (2012) used scanning electron microscopy to determine size and shape of wood dust from different softwood and hardwood species. Their results confirmed that dust particles have a range of complex shapes, with spherical shape not predominant.

Another possible reason for uncertainty about diffusivity is related to the first kind boundary condition used in the model proposed by Ritger and Peppas (1987). The boundary condition assumes that hygroscopic equilibrium is instantly obtained at the surface of wood dust particles. Olek et al. (2016) previously reported that thermal modification alters the mechanism by which wood achieves hygroscopic equilibrium. Unfortunately, it was not possible in the present analysis to consider the already developed concept of the modified convective boundary condition, which incorporates a relaxation term. Moreover, Olek et al. (2016) found that thermal modification was responsible for increased non-Fickian behavior, so that the simplest diffusion models were unable to satisfactorily describe non-Fickian processes.

\section{Conclusion}

Dynamic sorption experiments of beech wood dust from untreated and thermally modified material were an effective and accurate approach to obtain adsorption and desorption isotherms. Adsorption isotherms were used to design another set of sorption experiments for collecting data to estimate water diffusivity. The analyses led to the following conclusions: 
1. Thermal modification significantly decreased equilibrium moisture content of both smaller and larger size fractions of wood dust. The decrease was primarily caused by reduced primary sorption sites, as indicated by values of $M_{m}$ and $m_{G D W}$ in the GAB and GDW models, respectively. The hypothesis of reduced wood dust hygroscopicity due to thermal modification was also supported by stronger binding of water molecules in the monolayer, as shown by $C_{G A B}$ values. The hygroscopic properties of dust obtained from thermally modified wood were significantly different compared to dust from untreated material. Therefore, the interactions between thermally treated wood dust and moist air will influence dust transport and filtration. These factors should be accounted for when designing, improving and controlling wood dust removal processes.

2. The relation between thermal modification and water diffusivity was not clearly established. This was probably the result of the model applied to describe water diffusion in wood dust, which assumes the geometry of dust particles is spherical. However, dust particles have diverse shapes and may be irregular, conical, rectangular, cylindrical and spherical. Another problem related to the modeling of water diffusion in wood dust is the assumption of the first kind boundary condition. The instantaneous hygroscopic equilibrium of dust particles has to be questioned, even for small particles of wood dust and especially those from thermally modified material, because thermal modification alters hygroscopic equilibrium. The model used to estimate water diffusion in wood dust particles did not allow consideration of a convective boundary condition to account for non-Fickian behavior.

3. Decreased water diffusivity with increasing moisture content was significant only from the dry state to the maximum water content for water binding to primary sites, i.e., over the range of monolayer sorption. For water molecules being linked to the secondary sorption sites, water diffusivity was largely independent of moisture content. This relationship was found for all experimental options tested in sorption experiments, i.e., for untreated and thermally modified material and for small and large dust fractions. Therefore, wood dust filtration can be significantly influenced only for wood dust at lowest moisture contents, while the majority of abrasive sanding processes are carried out for wood with moisture content higher than ca. $7-8 \%$, at which there is limited influence of water-dust interactions. Another factor influencing filtration processes is particle size: The finest particles (wood dust fraction $<25 \mu \mathrm{m}$ ) had lower water diffusivity, being an order of magnitude less compared to wood dust particles of 80-250 $\mu \mathrm{m}$ diameter.

Acknowledgements The paper was financed within the framework of the Ministry of Science and Higher Education programme "Regional Initiative of Excellence" in years 2019-2022, Project No. 005/ RID/2018/19.

Open Access This article is licensed under a Creative Commons Attribution 4.0 International License, which permits use, sharing, adaptation, distribution and reproduction in any medium or format, as long as you give appropriate credit to the original author(s) and the source, provide a link to the Creative Commons licence, and indicate if changes were made. The images or other third party material in this article are included in the article's Creative Commons licence, unless indicated otherwise in a credit line to the material. If material is not included in the article's Creative Commons licence and your intended use is 
not permitted by statutory regulation or exceeds the permitted use, you will need to obtain permission directly from the copyright holder. To view a copy of this licence, visit http://creativecommons.org/licen ses/by/4.0/.

\section{References}

Altgen M, Hofmann T, Militz H (2016) Wood moisture content during the thermal modification process affects the improvement in hygroscopicity of Scots pine sapwood. Wood Sci Technol 50:1181-1195. https://doi.org/10.1007/s00226-016-0845-X

Aro MD, Geerts SM, French S, Cai M (2019) Particle size analysis of airborne wood dust produced from sawing thermally modified wood. Eur J Wood Prod 77:211-218. https://doi.org/10.1007/ s00107-019-01385-z

Basu S, Shivhare US, Mujumdar AS (2006) Models for sorption isotherms for food: a review. Dry Technol 24(8):917-930. https://doi.org/10.1080/07373930600775979

Boonstra MJ, Van Acker J, Tjeerdsma BF, Kegel EV (2007) Strength properties of thermally modified softwoods and its relation to polymeric structural wood constituents. Ann Sci 64:679-690. https:// doi.org/10.1051/forest:2007048

Chen C-C, Chen W-Y, Huang S-H, Lin W-Y, Kuo Y-M, Jeng F-T (2001) Experimental study on the loading characteristics of needlefelt filters with micrometer-sized monodisperse aerosols. Aerosol Sci Technol 34:262-273. https://doi.org/10.1080/02786820120458

Chirife J, Timmermann EO, Iglesias HA, Boquet R (1992) Some features of the parameter $k$ of the GAB equation as applied to sorption isotherms of selected food materials. J Food Eng 15(1):75-82. https://doi.org/10.1016/0260-8774(92)90041-4

Esteves BM, Pereira HM (2009) Wood modification by heat treatment: a review. BioResources 4(1):370-404

Furmaniak S, Terzyk AP, Gauden PA (2007a) The general mechanism of water sorption on foodstuffs - Importance of the multitemperature fitting of data and the hierarchy of models. J Food Eng 82(4):528-535. https://doi.org/10.1016/j.jfoodeng.2007.03.012

Furmaniak S, Terzyk AP, Gauden PA, Rychlicki G (2007b) Applicability of the generalised D'Arcy and Watt model to description of water sorption on pineapple and other foodstuffs. J Food Eng 79(2):718-723. https://doi.org/10.1016/j.jfoodeng.2006.02.036

Furmaniak S, Terzyk AP, Gauden PA (2008) Interrelation between steam sorption by wood and temperature. Drewno 51(180):15-29

Furmaniak S, Terzyk AP, Gauden PA (2011) Some remarks on the classification of water vapor sorption isotherms and Blahovec and Yanniotis isotherm equation. Dry Technol 29:984-991. https://doi.org/ 10.1080/07373937.2011.566399

Glass SV, Boardman CR, Zelinka SL (2017) Short hold times in dynamic vapor sorption measurements mischaracterize the equilibrium moisture content of wood. Wood Sci Technol 51(2):243-260. https://doi.org/10.1007/s00226-016-0883-4

Glass SV, Boardman CR, Thybring EE, Zelinka SL (2018) Quantifying and reducing errors in equilibrium moisture content measurements with dynamic vapor sorption (DVS) experiments. Wood Sci Technol 52(4):909-927. https://doi.org/10.1007/s00226-018-1007-0

Gómez Yepes ME, Cremades LV (2011) Characterization of wood dust from furniture by scanning electron microscopy and energy-dispersive x-ray analysis. Ind Health 49:492-500. https://doi.org/10. 2486/indhealth.ms1204

Gupta A, Novick VJ, Biswas P, Monson PR (1993) Effect of humidity and particle hygroscopicity on the mass loading capacity of high efficiency particulate air (HEPA) filters. Aerosol Sci Technol 19:94107. https://doi.org/10.1080/02786829308959624

Hajra MG, Mehta K, Chase GG (2003) Effects of humidity, temperature, and nanofibers on drop coalescence in glass fiber media. Sep Purif Technol 30:79-88. https://doi.org/10.1016/S1383-5866(02) 00134-X

Hess KM, Killgore JP, Srubar WV (2018) Nanoscale hygromechanical behavior of lignin. Cellulose 25(11):6345-6360. https://doi.org/10.1007/s10570-018-2045-3

Jacobsen G, Schaumburg I, Sigsgaard T, Schlünssen V (2010) Non-malignant respiratory diseases and occupational exposure to wood dust. Part II. Dry wood industry. Ann Agric Environ Med 17:29-44 
Jones D, Sandberg D (2020) A review of wood modification globally - updated findings from COST FP1407. Interdiscip Perspect Built Environ 1:1-31. https://doi.org/10.37947/ipbe.2020.vol1.1

Källbom S, Altgen M, Militz H, Wålinder M (2018) Sorption and surface energy properties of thermally modified spruce wood components. Wood Fiber Sci 50(3):346-357. https://doi.org/10.22382/ wfs-2018-033

Kocaefe D, Huang X, Kocaefe Y (2015) Dimensional stabilization of wood. Curr Rep 1:151-161. https:// doi.org/10.1007/s40725-015-0017-5

Lewicki PP (1997) The applicability of the GAB model to food water sorption isotherms. Int J Food Sci Technol 32(6):553-557. https://doi.org/10.1111/j.1365-2621.1997.tb02131.x

Liang T, Wang L (2016) Thermal treatment of poplar hemicelluloses at 180 to $220^{\circ} \mathrm{C}$ under nitrogen atmosphere. BioResources 12(1):1128-1135. https://doi.org/10.15376/biores.12.1.1128-1135

Majka J, Rogoziński T, Olek W (2019) Water sorption and diffusion properties of beech wood dust. Powder Technol 346:109-115. https://doi.org/10.1016/j.powtec.2019.02.007

Mazzoli A, Favoni O (2012) Particle size, size distribution and morphological evaluation of airborne dust particles of diverse woods by Scanning Electron Microscopy and image processing program. Powder Technol 225(6):65-71. https://doi.org/10.1016/j.powtec.2012.03.033

Meng E, Yin J, Jin W, Mao Y, Wu Q, Qiu J (2020) Wood dust exposure and risks of nasopharyngeal carcinoma: A meta-analysis. Eur J Public Health 30(4):817-822. https://doi.org/10.1093/eurpub/ ckz239

Morris K, Allen RWK (1996) The influence of dust and gas properties on cake adhesion in fabric filters. Filtr Sep 33:339-334. https://doi.org/10.1016/S0015-1882(97)84224-3

Mukhopadhyay A (2009) Pulse-jet filtration: an effective way to control industrial pollution Part I: Theory, selection and design of pulse-jet filter. Text Prog 41:195-315. https://doi.org/10.1080/00405 160903437948

Mukhopadhyay A (2010) Pulse-jet filtration: An effective way to control industrial pollution Part II: Process characterization and evaluation of filter media. Text Prog 42:1-97. https://doi.org/10.1080/ 00405160903438367

Očkajová A, Kučerka M, Kminiak R, Krišták L', Igaz R, Réh R (2020) Occupational exposure to dust produced when milling thermally modified wood. Int J Environ Res Public Health 17(5):1478. https:// doi.org/10.3390/ijerph17051478

Olek W, Bonarski JT (2014) Effects of thermal modification on wood ultrastructure analyzed with crystallographic texture. Holzforschung 68(6):721-726. https://doi.org/10.1515/hf-2013-0165

Olek W, Perré P, Weres J (2011) Implementation of a relaxation equilibrium term in the convective boundary condition for a better representation of the transient bound water diffusion in wood. Wood Sci Technol 45(4):677-691. https://doi.org/10.1007/s00226-010-0399-2

Olek W, Majka J, Czajkowski Ł (2013) Sorption isotherms of thermally modified wood. Holzforschung 67(2):183-191. https://doi.org/10.1515/hf-2011-0260

Olek W, Rémond R, Weres J, Perré P (2016) Non-Fickian moisture diffusion in thermally modified beech wood analyzed by the inverse method. Int J Therm Sci 109:291-298. https://doi.org/10.1016/j.ijthe rmalsci.2016.06.023

Park O, Yoo G, Seung B (2007) A lab-scale study on the humidity conditioning of flue gas for improving fabric filter performance. Korean J Chem Eng 24:717-722. https://doi.org/10.1007/ s11814-007-0032-8

Peppas NA, Brannon-Peppas L (1994) Water diffusion and sorption in amorphous macromolecular systems and foods. J Food Eng 22(1-4):189-210. https://doi.org/10.1016/0260-8774(94)90030-2

Pfriem A, Zauer M, Wagenführ A (2010) Alteration of the unsteady sorption behaviour of maple (Acer pseudoplatanus L.) and spruce (Picea abies (L.) Karst.) due to thermal modification. Holzforschung 64(2):235-241. https://doi.org/10.1515/hf.2010.029

Piernik M, Rogoziński T, Krauss A, Pinkowski G (2019) The influence of the thermal modification of pine (Pinus sylvestris L.) wood on the creation of fine dust particles in plane milling: Fine dust creation in the plane milling of thermally modified pine wood. J Occup Health 61(6):481-488. https:// doi.org/10.1002/1348-9585.12075

Ritger PL, Peppas NA (1987) A simple equation for description of solute release. I. Fickian and nonfickian release from non-swellable devices in the form of slabs, spheres, cylinders or discs. J Control Release 5(1):23-36. https://doi.org/10.1016/0168-3659(87)90034-4

Schmidt E, Pilz T (1996) Raw gas conditioning and other additional techniques for improving surface filter performance. Filtr Sep 33:409-415. https://doi.org/10.1016/S0015-1882(97)84301-7 
Simon X, Bémer D, Chazelet S, Thomas D (2014) Downstream particle puffs emitted during pulse-jet cleaning of a baghouse wood dust collector: Influence of operating conditions and filter surface treatment. Powder Technol 261:61-70. https://doi.org/10.1016/j.powtec.2014.04.028

Taylor JR (1997) An introduction to error analysis. The study of uncertainties in physical measurements, 2nd edn. University Science Books, Sausalito

Timmermann EO (2003) Multilayer sorption parameters: BET or GAB values? Colloid Surf A 220(13):235-260. https://doi.org/10.1016/S0927-7757(03)00059-1

Wagenführ R (2006) Holzatlas (Wood atlas) (In German). 6th Ed. Fachbuchverlag Leipzig.

Yuan J, Chen Q, Fei B (2021) Investigation of the water vapor sorption behavior of bamboo fibers with different sizes. Eur J Wood Prod 79:1131-1139. https://doi.org/10.1007/s00107-020-01652-4

Publisher's Note Springer Nature remains neutral with regard to jurisdictional claims in published maps and institutional affiliations. 